\title{
Letter to the Editor: Methodology for Bilirubin Binding Studies
}

\author{
LEO STERN ${ }^{(3)}$ \\ Brown University, Rhode Island Hospital-Providence, Providence, Rhode Island, USA
}

The paper by Ainbender and colleagues (A Paper Chromatoelectrophoresis Method for the Determination of Bilirubin Binding to Serum Protein) in Pediatric Research, volume 11, pages 808-811, proposes a method of determination of bilirubin binding capacity, which, although it does represent a newer technologic approach to the utilization of the system, is dependent upon the original observation made by our Czech colleagues $(1,2)$ a number of years ago, regarding the possibility of separating free from albumin-bound bilirubin on the basis of differential migration on electrophoretic paper. One would have liked to see reference to their earlier publications in this area, since while granting that the current description represents a more sophisticated application of these principles, credit for the idea upon which this is based should

Copyright $(1978$ International Pediatric Research Foundation. Inc. $0031-3998 / 78 / 1206-0731 \$ 02.00 / 0$ be properly awarded in describing the methodology.

One can only assume that this is an oversight on their part, and one would hope that the authors would move to correct it.

\section{REFERENCES AND NOTES}

1. Novak, M., Polacek, K., and Melichar, V.: Competition between bilirubin and nonesterified fatty acids for binding bilirubin to albumin. Biol. Neonate. 4: $310(1962)$.

2. Polacek, K.. Novak, M., and Melichar, V.: Influence of FFA on the distribution of bilirubin and its clinical significance in the newborn. Rev. Czech. Med., 11 : 161 (1965).

3. To whom correspondence should be addressed.

4. Received for publication September 12,1977. *

Pediat. Res. 12: 731 (1978)

\section{Letter to the Editor: Reply to Dr. Stern}

\author{
EUGENE AINBENDER, ${ }^{(1)}$ EDWIN G. BROWN, AND AVRON Y. SWEET
}

Mount Sinai School of Medicine, of The City University of New York, New York, New York, USA

Thank you for sending Dr. Stern's letter on to us. We are pleased that he read our paper with such care.

It was not our purpose to present a comprehensive review of the techniques for the estimation of bilirubin binding nor of all work upon which our method was based. That would have been lengthy, unnecessary and editorially unacceptable.

We focused on publications which dealt with quantitation. Dr. Novak and his coworkers, whose work is well known, demonstrated by electrophoresis the unbinding of bilirubin by fatty acids but there was no attempt at quantitation.

We very carefully cited the earliest work upon which our method was built, namely that of Bennhold (Ergeb. Inn. Med.
Kinderh., 42: 273 (1932)) and we referred to the most recent work (Athanassiadis and coworkers in J. Lab. Clin. Med., 83: 968 (1974)). In between were left unmentioned many authors from B. Childs through U. Westphal as well as a large number of journals from Biology of the Neonate through Zeitschrift fuer Physiologische Chemie (Hoppe-Seyler's).

To all those unsung workers to whom we failed to give due credit, we apologize for an unintentional snub.

\section{NOTES}

1. To whom correspondence should be addressed.

2. Received for publication October 12, 1977. 